\title{
Analysis and Synthesis of Islamic Geometric Designs
}

\author{
Brian Wichmann \\ United Kingdom \\ brian.wichmann@bcs.org.uk
}

Tony Lee

United Kingdom

\section{INTRODUCTION}

We have been working on the web site www.tilingsearch.org for the past five years or so, and one of our aims has been to provide documentation on as many of the classical Islamic patterns as we can discover, from many sources (we already have over 1200 of these, and we think there may be at least 2000). For each pattern, part of the documentation consists of the results of sequences of trigonometrical formulae relating to the edge lengths of individual polygons within the pattern, to enable our computer software to build up a complete two-dimensional design. As a preliminary to working out the formulae, we attempt an analysis of the patterns along mathematical lines - as far as this is possible - and here we encounter one of the major difficulties in treating all Islamic patterns as though they were complicated diagrams in a geometry textbook.

Some Islamic patterns can be redrawn as though they had a very precise underlying geometry, and these determinate patterns lend themselves naturally to an exact trigonometrical analysis. But perhaps the majority of existing patterns belong to an indeterminate class, in which at least some proportions and angles are arbitrarily chosen, either based on purely aesthetic considerations, or because of various geometrical incompatibilities in their choice of motifs. In order to produce accurate computer graphic images of this latter class we have to make our own choices as to angles and lengths within the individual polygons of each design. In other words, some synthesis is needed. Depending on the looseness of the construction of the original pattern, the synthesis be a fairly straightforward procedure, or it may require many trials before a satisfactory graphic can be produced.

\section{ANALYSIS}

We present examples of determinate patterns, and of varying degrees of arbitrariness and consequent difficulty among indeterminate patterns. We consider four patterns: a fully determinate one Shah-i-Zinda complex, Mausoleum No 15, Samarkand (Fig. 1) Hill (1964); another fully determinate one using a decagonal base, Bourgoin, Plate 171 (Fig. 2) Bourgoin (1879); an indeterminate pattern using the same decagonal base Great Mosque, Damascus (Fig. 3) Wade (2007); and finally one that, although in Islamic style, is a modern pattern which defies mathematical analysis (Fig. 4) Voirol (2007).

\section{CONCLUSIONS}

Islamic geometric patterns are not always easy to analyse in mathematical terms. When an analysis is possible, the resulting properties provide a basis for a search tool, as to be found on our website (http://www.tilingsearch.org). A full paper entitled "Drawing an Islamic Pattern" can be found on our website at: http://www.tilingsearch.org/draw4.pdf

\section{REFERENCES}

Bourgoin, J. (1879) Arabic Geometrical Pattern and Design. Dover Publications, ISBN 048622924.

Hill, D. (1964) Islamic architecture and its decoration, A.D. 800-1500. Faber and Faber.

Wade, D. (2007) Pattern in Islamic Art. http://www.patterninislamicart.com (retrieved 14 June 2013).

Nathan, V. (2007) Sa'odat (Happiness). In Mathematical Art Exhibition. AMS, USA, 2009. http://www. bridgesmathart.org/artexhibits/jmm09/voirol.html (retrieved 14 June 2013). 


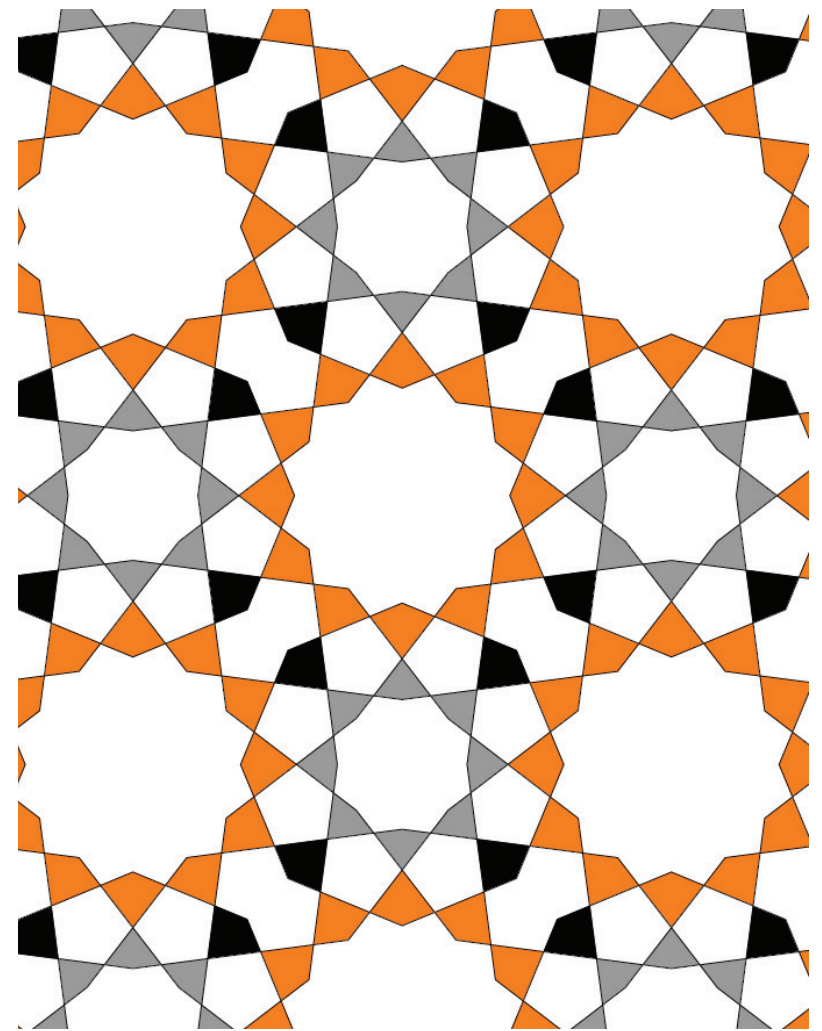

Figure 1: Shah-i-Zinda complex, Mausoleum No 15, Samarkand

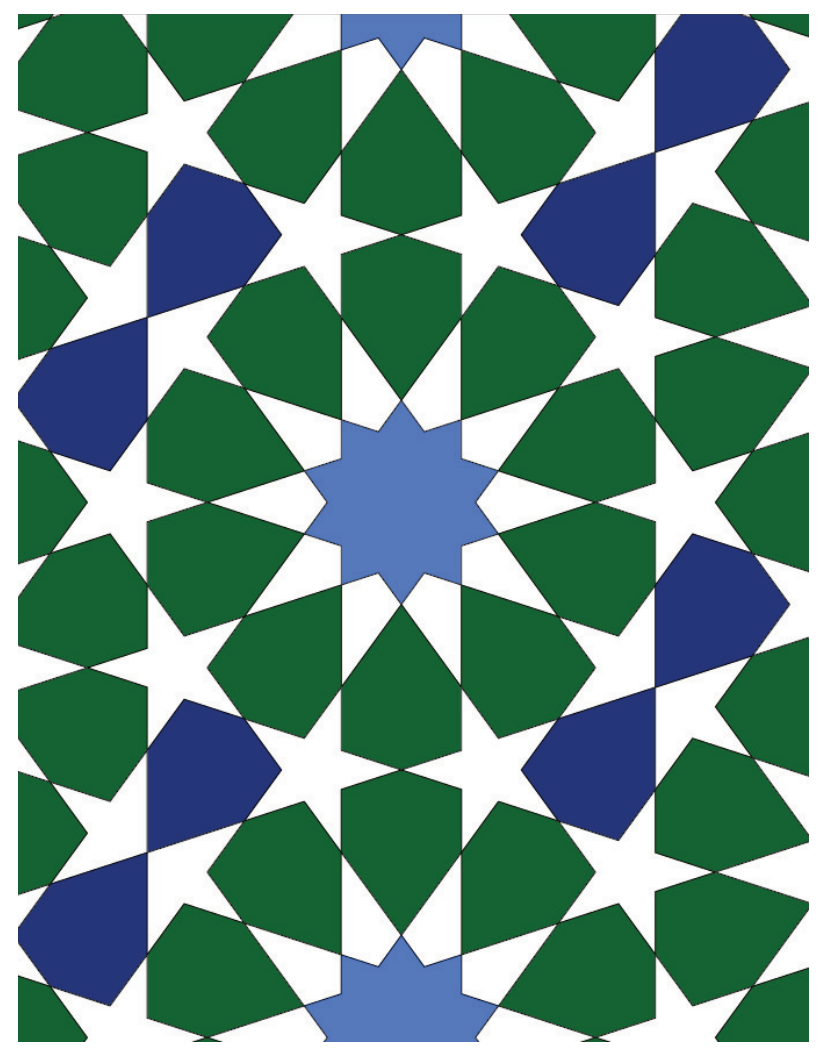

Figure 2: Bourgoin, Plate 171

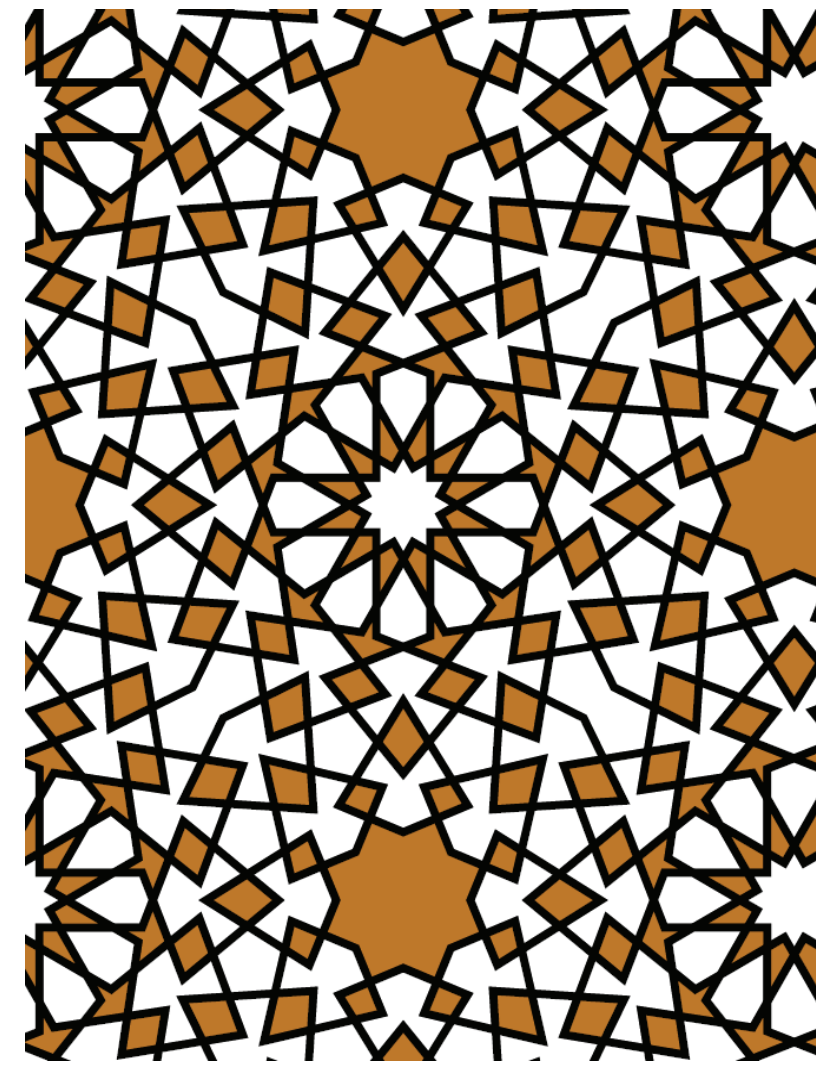

Figure 3: Great Mosque, Damascus

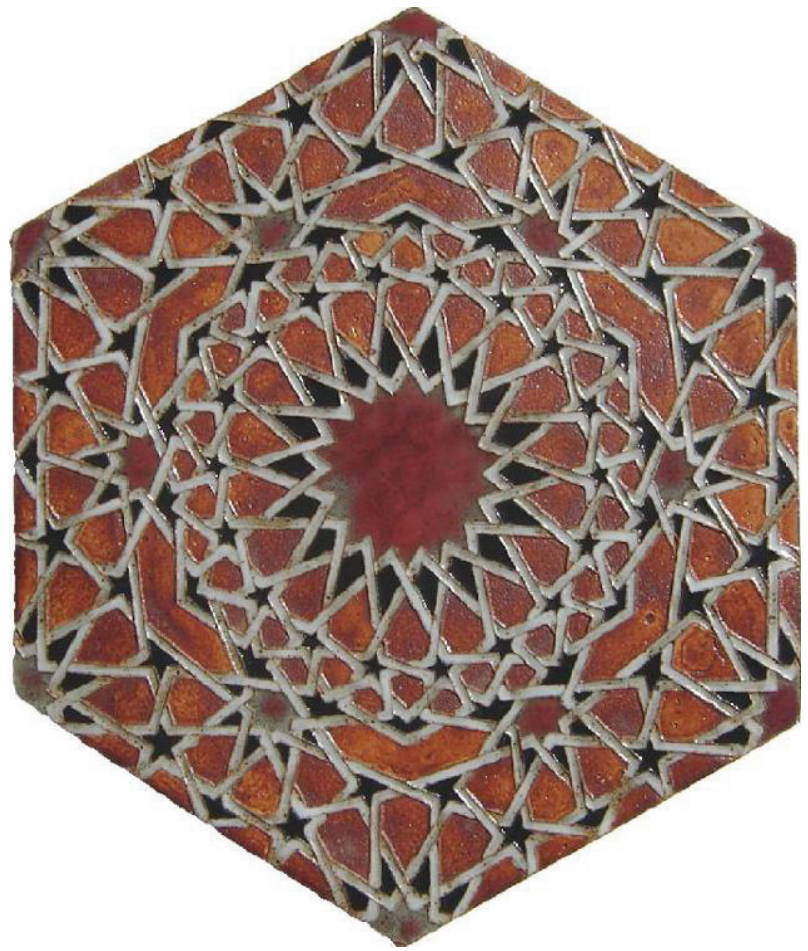

Figure 4: Sa'odat (Happiness) (c) Nathan Voirol 